\title{
Features of small intestinal pathology (epithelial cell kinetics, intraepithelial lymphocytes, disaccharidases) in a primary Giardia muris infection
}

\author{
J GILLON, D AL THAMERY, ${ }^{*}$ and ANNE FERGUSON $\dagger$ \\ From the Gastro-Intestinal Unit, University of Edinburgh and Western General Hospital, Edinburgh
}

SUMMARY In an attempt to correlate host and parasite-related events occurring during the course of a primary Giardia infection in the mouse we have measured epithelial cell kinetics, enzymes, and intraepithelial lymphocytes at different stages of the infection. New methods were developed for the accurate measurement of parasite numbers and distribution within the gut. In jejunum a modest decrease in villus length and intraepithelial lymphocytes at week 1 preceded a pronounced disaccharidase deficiency at week 2 , the time of maximum trophozoite numbers, whereas crypt lengthening and increased cell production became maximal at week 3 . As trophozoite numbers fell the intraepithelial lymphocyte count and disaccharidase values rose. With the exception of the intraepithelial lymphocyte count, which followed the same pattern as in jejunum but two weeks later, the changes seen in the ileum were the opposite of those in jejunum, suggesting rapid ileal adaptation. The results indicate that the disaccharidase deficiency associated with giardiasis is likely to represent a direct effect of the parasite on the brush border rather than enterocyte immaturity, whereas the intraepithelial lymphocyte response reflects host immunity to the parasite. Profound adaptive changes occur throughout the small intestine in response to a relatively localised insult.

Infection with Giardia lamblia may be entirely asymptomatic, may produce a mild, self-limiting illness, or chronic diarrhoea with or without malabsorption. The reasons for this variation in severity are unknown at present, but among the possible causes to be considered are variations in parasite virulence, associated bacterial overgrowth in the small intestine, nutritional status, and other host factors such as the type of the immune response and its effect on the intestinal mucosa. Various abnormalities of small bowel pathology have been identified consistently in giardiasis, and these include disaccharidase deficiencies, ${ }^{12}$ increased intraepithelial lymphocyte counts ${ }^{34}$ and, in patients with malabsorption, crypt hyperplasia with short villi and increased lamina propria cellularity. ${ }^{5}{ }^{6}$ The severity of the mucosal changes in a biopsy of proximal jejunum appears to correlate with the

\footnotetext{
* On leave from the Department of Paediatrics, Basrah Medical College, Iraq. + Address for correspondence and reprint requests: Dr J Gillon, Gastrointestinal Unit, Western General Hospital, Edinburgh EH4 2XU.

Received for publication 19 October 1981
}

overall degree of malabsorption, ${ }^{2}{ }^{78}$ despite the fact that the distribution of the parasite along the small intestine in man is unknown, and the proximal jejunum may not necessarily be representative of the mucosa of the whole small bowel.

Giardiasis affects many other species, including laboratory rodents. Murine giardiasis is a useful experimental system for studies of host parasite relationships, for it is possible to document the magnitude and time-course of infection by cyst and trophozoite counts. ${ }^{9}$ We have previously reported ${ }^{10}$ that in chronic murine giardiasis the intraepithelial lymphocyte count is increased, epithelial cell kinetics are altered, and tissue sucrase activity is reduced. These features are similar to those in the jejunum in 'mild' human disease.

In the experiments described in this paper we have examined the progression of changes in epithelial cell kinetics, enzymes, and intraepithelial lymphocytes during a primary Giardia muris infection. The objectives have been to establish which, if any, of the pathological features appear to be correlated with the magnitude of the parasite 
infection at that site, and whether any of these features are likely to be due to mechanisms other than the direct effect of the parasite. In particular, we were interested in the possible role of the immune response as a mechanism of tissue damage.

\section{Methods}

\section{ANIMALS}

CBA mice (male and female) between 8 and 10 weeks of age at the time of infection were used. They had free access to tap water and pelleted rodent diet (Strats mouse pellets providing $4 \cdot 2$ calories/g, protein content $21.3 \%$ ). Faecal specimens and intestinal contents of stock CBA mice were checked regularly to confirm the absence of protozoal and helminth infections in the colony.

\section{GIARDIA MURIS INFECTION}

Giardia muris cysts were provided by Dr I RobertsThompson and flown from Australia to the United Kingdom by airmail. Stock mice were infected by oral inoculation of 1000 cysts, and the infection maintained by weekly inoculation of two or three adult CBA mice. For all experiments, CBA mice aged 8 to 10 weeks were infected by intragastric administration of 1000 Giardia muris cysts in $0.2 \mathrm{ml}$ tap water. Cysts were isolated and counted by the method of Roberts-Thompson et $a l^{9}$ described below.

\section{CYST COUNTS}

A two-hour faecal collection was obtained from each mouse by isolating it within a plastic tub for two hours. Faeces were then broken up in tap water and the faecal suspension layered on molar sucrose of specific gravity $1 \cdot 11$, and centrifuged at $400 \mathrm{~g}$ for 15 minutes. Cysts, concentrated at the water-sucrose interface, were removed, washed in normal saline and resuspended in a known volume before counting in a haemocytometer. With this technique the limit of detection is 1000 cysts per specimen.

\section{TROPHOZOITES: HISTOLOGY}

In animals which were used for measurements of epithelial cell kinetics and disaccharidases, the presence of trophozoites in the intestine was confirmed histologically or by direct smear of jejunal contents.

\section{TROPHOZOITE COUNTS: VIBRATION METHOD}

Accurate trophozoite counts were performed in other batches of animals, by a vibration method. The animal is killed, the small intestine removed intact, and the mesentery peeled off. The gut is then everted on a spiral rod of glass or steel, exposing the luminal surface, and the ends tied with silk sutures. The top part of the spiral rod is then connected to a Chemap AG Vibromix Model Type E1, which has a vibration frequency of $50 \mathrm{~Hz}$. The spiral is then placed in a dish containing $100 \mathrm{ml}$ of fluid $(98 \mathrm{ml}$ normal saline, $2 \mathrm{ml}$ acetyl cysteine Airbron) at $4^{\circ} \mathrm{C}$. The intestine is then vibrated in medium for 10 minutes at the full power of the Vibromix, a $10 \mathrm{ml}$ sample of medium removed, centrifuged at $400 \mathrm{~g}$ for 10 minutes, the supernatant discarded, the pellet resuspended in $0.5 \mathrm{ml}$ of medium and the trophozoites counted in a haemocytometer. The total trophozoite count $/ 100 \mathrm{ml}$ - that is, per intestine - is calculated. With this technique the limit of detection is 10000 trophozoites/animal.

\section{TROPHOZOITE COUNT: SIEVE METHOD}

In order to define the distribution of trophozoites along the intestine, another technique was used in a small number of animals. The whole small intestine was removed and its length measured. Beginning at the gastroduodenal junction, segments of whole intestine $1 \mathrm{~cm}$ in length were taken, discarding $2 \mathrm{~cm}$ between each. Thus counts were performed on one-third of the entire intestine. Each $1 \mathrm{~cm}$ segment was mashed through a stainless steel grid with holes of $50 \mu \mathrm{m}$ diameter, using a glass rod, and washed through with $1 \mathrm{ml}$ normal saline from a syringe and needle. Aliquots of the resulting suspension were then examined and a trophozoite count performed in a Neubauer haemocytometer.

MEASUREMENTS OF EPITHELIAL CELL KINETICS AND INTESTINAL ARCHITECTURE

A stathmokinetic technique, using colchicine blockage and microdissection, was used. A group of mice (10-15 in most experiments) was taken and colchicine $(\mathrm{BDH})$ injected, $5 \mathrm{mg} / \mathrm{kg}$ body weight, intraperitoneally. Mice were killed by ether overdosage or cervical dislocation at intervals from 30 minutes to $2 \frac{1}{2}$ hours later and a piece of jejunum, 10 $\mathrm{cm}$ from the pylorus, and a piece of ileum, $5 \mathrm{~cm}$ from the ileocaecal valve, were dissected out and fixed in a $75 \%$ absolute alcohol, $25 \%$ glacial acetic acid mixture, for 24 hours. Tissues were then transferred to $75 \%$ alcohol until processed for measurements of villus length, crypt length, and metaphases/crypt.

For measurements of crypts and villi, tissues were stained in bulk by an adaptation of the Feulgan technique of Wimber and Lamerton. ${ }^{12}{ }^{13}$ The tissues were stained as follows: $50 \%$ alcohol 10 minutes; tap water 10 minutes; hydrolysis in molar $\mathrm{HCl}$ at $60^{\circ} \mathrm{C}$ six minutes; tap water 10 minutes; Schiff reagent 20 minutes; then stored in tap water until examined. With a dissecting microscope the tissue was 
orientated and one or two villi with their surrounding crypts were cut from the edge by careful dissection with a scalpel and fine forceps, placed on a slide in $45 \%$ acetic acid, and lengths of villi and crypts measured by a calibrated micrometer eyepiece. For each specimen 10 measurements of villus length and of crypt length were made and the mean value obtained.

In order to count metaphases, a fragment of the tissue was placed on a slide in $45 \%$ acetic acid and gently squashed with a coverslip. The number of metaphases/crypt was counted. Metaphase blockage was found in every specimen examined. For each specimen the number of metaphases in 10 crypts was counted and the mean value obtained. The crypt cell production rate was calculated from the slope of the regression line, drawn using the method of least squares, of metaphase count against time after colchicine injection.

\section{HISTOLOGY AND INTRAEPITHELIAL LYMPHOCYTE COUNTS}

At the same time as specimens were taken for epithelial cell kinetic measurements, adjacent segments of jejunum and ileum were fixed in formol saline and paraffin embedded, $5 \mu \mathrm{m}$ sections were cut and stained with haematoxylin and eosin. Intraepithelial lymphocyte counts were performed by a differential count in the epithelium covering the villi, in well-orientated $\mathrm{H}$ and $\mathrm{E}$ stained sections. Results were expressed as lymphocytes/100 epithelial cells. ${ }^{15}$ In addition, an assessment of the heaviness of Giardia infection was made, scoring each section as containing many trophozoites (confluent sheets of trophozoites in the mucus over the villi), few trophozoites (single organisms, at least one or two per villus, and readily seen), or no trophozoites (no parasites seen in six to eight high power fields.

\section{DISACCHARIDASE ASSAY}

Tissues for disaccharidase assay were taken from jejunum around $10 \mathrm{~cm}$ from the pylorus, and ileum, $5 \mathrm{~cm}$ from the ileocaecal valve. The full thickness specimen of intestine was weighed, homogenised in ice-cold maleate buffer, and the disaccharidases lactase, sucrase, and maltase assayed by the technique of Dahlqvist. ${ }^{16}$

\section{STATISTICAL ANALYSIS}

In all studies the overall significance of the results was first assessed by parametric and non-parametric one way analyses of variance (F-test and KruskallWallis respectively). Where appropriate individual groups were then compared using Student's $t$ test.

\section{Results}

TIME-COURSE OF INFECTION AND DISTRIBUTION OF TROPHOZOITES

In order to establish the typical time-course of infection in the strain of mice used for the experiments, the pattern of cyst excretion after infection with 1000 cysts was examined in eight CBA mice at one, two, three, four, and six weeks post-infection. In addition cyst counts were carried out in 50 CBA mice which had been infected between three and 11 months previously, for the maintenance of a stock of infected animals.

Thirty-seven infected mice were killed at intervals up to six weeks post-infection (six to nine animals/ group) and in each animal the total small intestinal trophozoite load was measured by the vibration technique. A further 18 stock CBA mice, three to 11 months post-infection, were killed and trophozoites counted by this vibration technique.

Results are shown in Fig. 1. Results of cyst counts show the pattern of cyst excretion to be very similar to previous reports, with peak cyst excretion at two weeks, and cysts undetectable in the majority of animals after four weeks. The number of trophozoites also reached a peak at two weeks postinfection, with values in some animals as high as $15-18 \times 10^{6}$. Trophozoites were also found in substantial numbers at six weeks post-infection, when cysts were no longer detected in faeces, and were also present in $50 \%$ of the animals studied at three

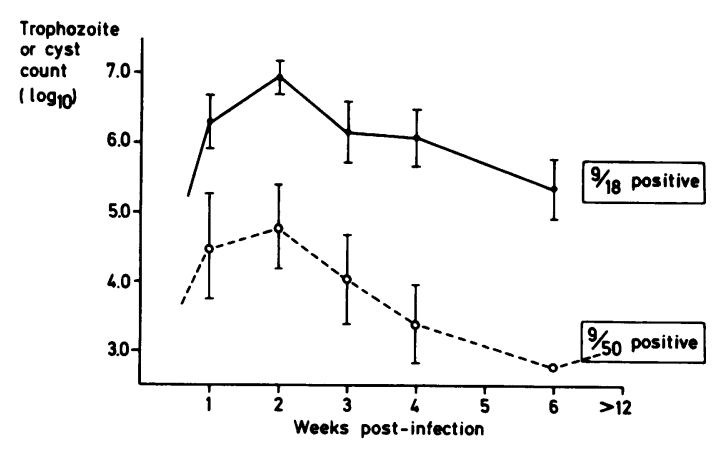

Fig. 1 Cyst excretion (two hour collection) and intestinal trophozoite count (vibration method) in CBA mice at intervals after infection with 1000 cysts of Giardia muris. Mean \pm standard error, six to nine animals per group. The numbers at $>12$ weeks indicate proportion of animals in which either trophozoites or cysts were detected, $>12$ weeks after a primary infection. (Values for positive cyst counts ranged 1000-8000; values for positive trophozoite counts ranged 10 000-170 000.) - Trophozoites (per animal). $\circ$ Cysts (two hour faeces collection). 
or more months post-infection. The distribution of parasites along the small intestine was examined at intervals from six to 35 days after infection, and the results in three representative animals, infected six, 14, and 35 days previously, are summarised in Fig. 2. The findings confirm the previously reported observations, that the greatest number of trophozoites are to be found in the proximal small bowel, although early in infection substantial numbers (several thousand trophozoites/cm segment) were present in the ileum. As the infection progressed the localisation became more obviously confined to the upper jejunum.

In Table 1 the results of studies in histological sections of jejunum and ileum are summarised, over the 10 weeks after primary infection of CBA mice with 1000 Giardia muris cysts. It is clear that, just as was shown by the quantitative assay, the highest numbers of trophozoites are present in the jejunum in the first four weeks post-infection, with few or no parasites visible at eight and 10 weeks. In the ileum, confluent sheets of trophozoites were seen in only four of the 13 mice examined at one week postinfection, and few trophozoites were present in the majority of animals at one to four weeks postinfection.

\section{EFFECTS OF PRIMARY GIARDIA MURIS INFECTION} ON THE LENGTHS OF VILLI AND CRYPTS

For this experiment, batches of 10-15 mice/group were infected with 1000 Giardia muris cysts orally; a group of animals was killed at one, two, three, four, six, eight, and 10 weeks post-infection. One batch of control, uninfected mice was also studied. Each mouse was given intraperitoneal colchicine and killed at a measured time interval thereafter, and specimens of jejunum and ileum taken for microdissection, and for histology as described below.

Results of the measurements of crypts and villi in

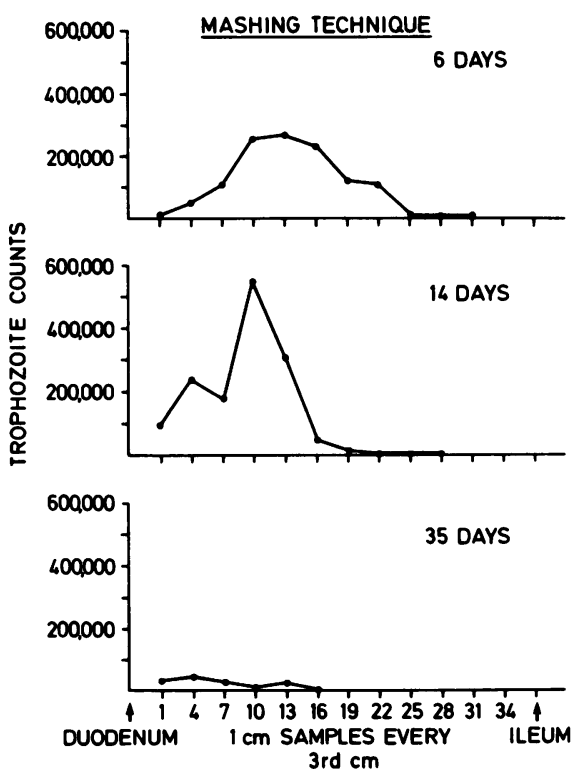

Fig. 2 Distribution of Giardia trophozoites along the length of the small intestine in three CBA mice, six, 14, and 35 days after infection with 1000 cysts of Giardia muris (for method see text).

jejunum and ileum are summarised in Figs. 3 and 4. Results for jejunum show significant shortening of villi only at one week post-infection $(\mathrm{p}<0.01)$, mean villus length being reduced from $690 \mu \mathrm{m}$ to $630 \mu \mathrm{m}$. Villi were significantly longer $(p<0.05)$ than controls at four, six, eight, and 10 weeks postinfection. Significant crypt lengthening was also found between one and four weeks post-infection.

Results for the ileum showed a different pattern. Information is available for only five groups of animals (because of deterioration of other speci-

Table 1 Trophozoites $(T z)$ in histological sections of jejunum and ileum in CBA mice infected with 1000 Giardia muris cysts

\begin{tabular}{|c|c|c|c|c|c|c|c|c|}
\hline \multirow{3}{*}{$\begin{array}{l}\text { Experimental } \\
\text { group } \\
\text { (weeks post- } \\
\text { infection) }\end{array}$} & \multicolumn{4}{|l|}{ Jejunum } & \multicolumn{4}{|l|}{ Ileum } \\
\hline & \multirow{2}{*}{$\begin{array}{l}\text { Total } \\
\text { number of } \\
\text { specimens } \\
\text { examined }\end{array}$} & \multicolumn{3}{|c|}{$\begin{array}{l}\text { Number of } \\
\text { specimens with: }\end{array}$} & \multirow{2}{*}{$\begin{array}{l}\text { Total } \\
\text { number of } \\
\text { specimens } \\
\text { examined }\end{array}$} & \multicolumn{3}{|c|}{$\begin{array}{l}\text { Number of } \\
\text { specimens with: }\end{array}$} \\
\hline & & Many $T z$ & Few $T z$ & None & & Many $T z$ & Few $T z$ & None \\
\hline 1 & 14 & 12 & 2 & - & 13 & 4 & 7 & 2 \\
\hline 2 & 15 & 15 & - & - & 15 & - & 13 & 2 \\
\hline 3 & 15 & 14 & 1 & - & 14 & - & 8 & 6 \\
\hline 4 & 15 & 14 & - & 1 & 16 & - & 6 & 10 \\
\hline 6 & 16 & 8 & 8 & - & 15 & - & - & 12 \\
\hline 8 & 13 & 1 & 5 & 7 & 12 & - & - & 12 \\
\hline 10 & 10 & 1 & 2 & 7 & 12 & - & - & 12 \\
\hline
\end{tabular}




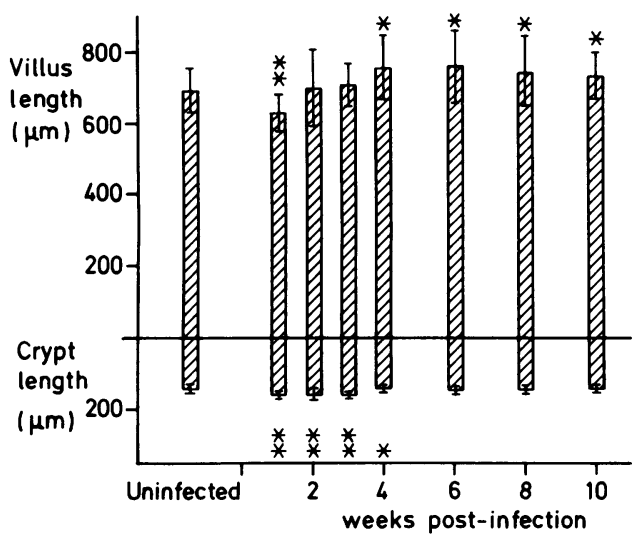

Fig. 3 Diagrammatic representation of architecture of jejunal mucosa in groups of mice either uninfected, or at intervals of one to 10 weeks after infection with Giardia muris. Ten to 15 mice per group. (Mean $\pm S D$. In this and the following figures single asterisk $=p<0.05$, double asterisk $=p<0 \cdot 01)$.

mens in storage) and show significant shortening of both villi and crypts at eight and 10 weeks postinfection.

EFFECT OF PRIMARY GIARDIA MURIS INFECTION ON CRYPT CELL PRODUCTION RATE (CCPR) IN

JEJUNUM AND ILEUM

Results of the measurement of epithelial cell kinetics are summarised in Table 2. Metaphase accumulation was linear in all groups over the period studied, and the jejunal CCPR for the batch control animals was 6.2 mitoses/crypt/hour. Values were higher in jejunum of mice at one, two, three, four, and eight weeks post-infection, but the only result which approached statistical significance was that at three weeks with $p$ value between 0.1 and $0 \cdot 05$.

The crypt cell production rate was higher in the

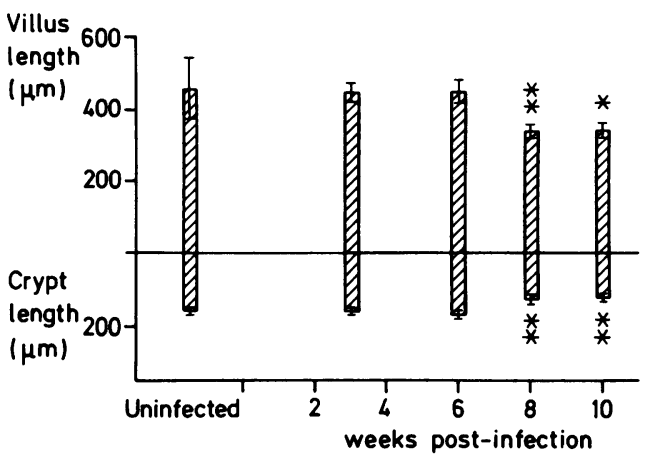

Fig. 4 Diagrammatic representation of architecture of ileal mucosa in groups of mice either uninfected, or at intervals of one to 10 weeks after infection with Giardia muris. Ten to 15 mice per group.

ileum than in the jejunum of control animals, being $8.6 \mathrm{mitoses} /$ crypt/hour. In the ileum significantly lower values were present in the batches of mice killed at three, eight, and 10 weeks post-infection.

EFFECT OF PRIMARY GIARDIA MURIS INFECTION ON DISACCHARIDASE CONTENT OF JEJUNUM AND

ILEUM

Assays of tissue disaccharidases were carried out in a different batch of mice from those used in the epithelial cell kinetic study. There were nine uninfected animals, and groups of four mice which had been infected with 1000 Giardia muris cysts one, two, three, four, six, eight, and 10 weeks previously. In contrast with the minimal effect of the infection on intestinal architecture, striking and significant disaccharidase changes were obtained (Figs. 5 and 6).

At two weeks post-infection, lactase, sucrase, and maltase levels in the jejunum were significantly lower than in control animals. At six, eight, and 10 weeks the disaccharidase content was higher than in

Table 2 Crypt cell production rate (CCPR) in jejunum and ileum of CBA mice infected with 1000 Giardia muris cysts

\begin{tabular}{|c|c|c|c|c|}
\hline \multirow{2}{*}{$\begin{array}{l}\text { Experimental } \\
\text { group } \\
\text { (weeks post- } \\
\text { infection) }\end{array}$} & \multicolumn{2}{|c|}{$C C P R-j e j u n u m$} & \multicolumn{2}{|l|}{ CCPR-ileum } \\
\hline & $\begin{array}{l}\text { Accumulated } \\
\text { metaphases/ } \\
\text { crypt/hour }\end{array}$ & $\begin{array}{l}p(\text { versus } \\
\text { uninfected })\end{array}$ & $\begin{array}{l}\text { Accumulated } \\
\text { metaphases/ } \\
\text { crypt/hour }\end{array}$ & $\begin{array}{l}p(\text { versus } \\
\text { uninfected })\end{array}$ \\
\hline & $6 \cdot 2$ & & $8 \cdot 6$ & \\
\hline 1 & $7 \cdot 1$ & NS & - & \\
\hline 2 & $7 \cdot 0$ & NS & - & \\
\hline 3 & $8 \cdot 2$ & $0.05<p<0.1$ & $5 \cdot 5$ & $0.05<\mathrm{p}<0.1$ \\
\hline 4 & $7 \cdot 5$ & NS & - & \\
\hline 6 & $5 \cdot 9$ & NS & $6 \cdot 6$ & NS \\
\hline 8 & $7 \cdot 0$ & NS & $5 \cdot 0$ & $\mathrm{p}<0.02$ \\
\hline 10 & $5 \cdot 8$ & NS & $5 \cdot 3$ & $\mathrm{p}<0.05$ \\
\hline
\end{tabular}




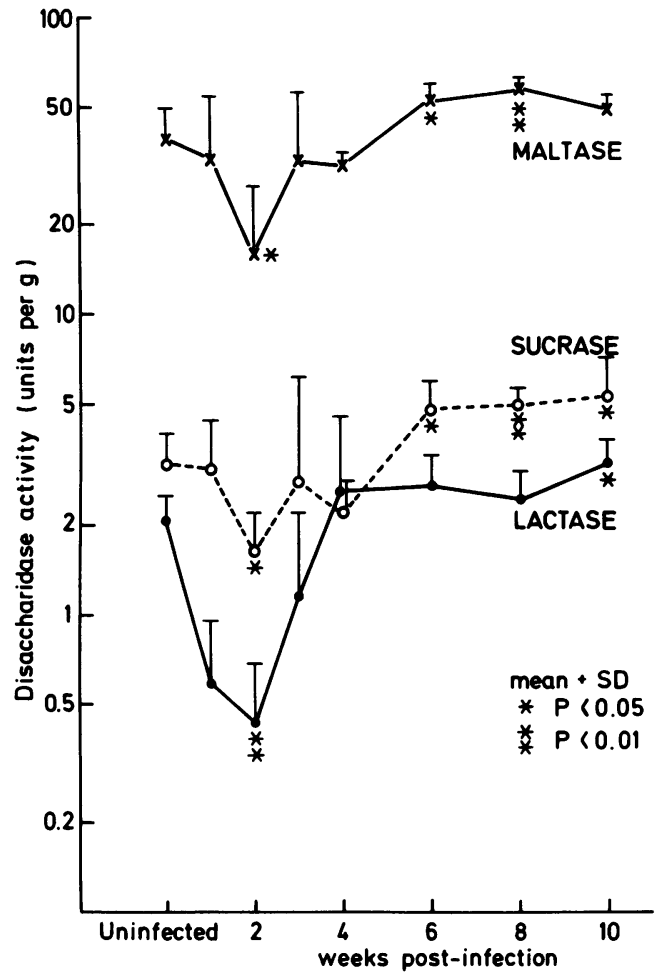

Fig. 5 Effects of primary Giardia muris infection on disaccharidase content of jejunal mucosa, in CBA mice either uninfected, or at intervals from one to 10 weeks after Giardia muris infection.

the control mice. In the ileum the only abnormality in the early phase post-infection was a significant increase in lactase at one week and sucrase at two weeks post-infection. Significantly low values for lactase and sucrase, however, were obtained in specimens taken at six, eight, and 10 weeks postinfection (Fig. 6).

\section{EFFECTS OF PRIMARY GIARDIA MURIS INFECTION ON INTRAEPITHELIAL LYMPHOCYTE COUNTS IN JEJUNUM AND ILEUM}

Counts of intraepithelial lymphocytes were performed in six uninfected mice, and in groups of six infected one, two, three, four, six, eight, and 10 weeks previously. The results are summarised in Fig. 7. In the jejunum there was a significant reduction in the intraepithelial lymphocyte count at one week, but by three weeks the counts were significantly raised, and remained so thereafter. In the ileum a significant fall occurred at three weeks, and raised counts were obtained from six weeks onwards.

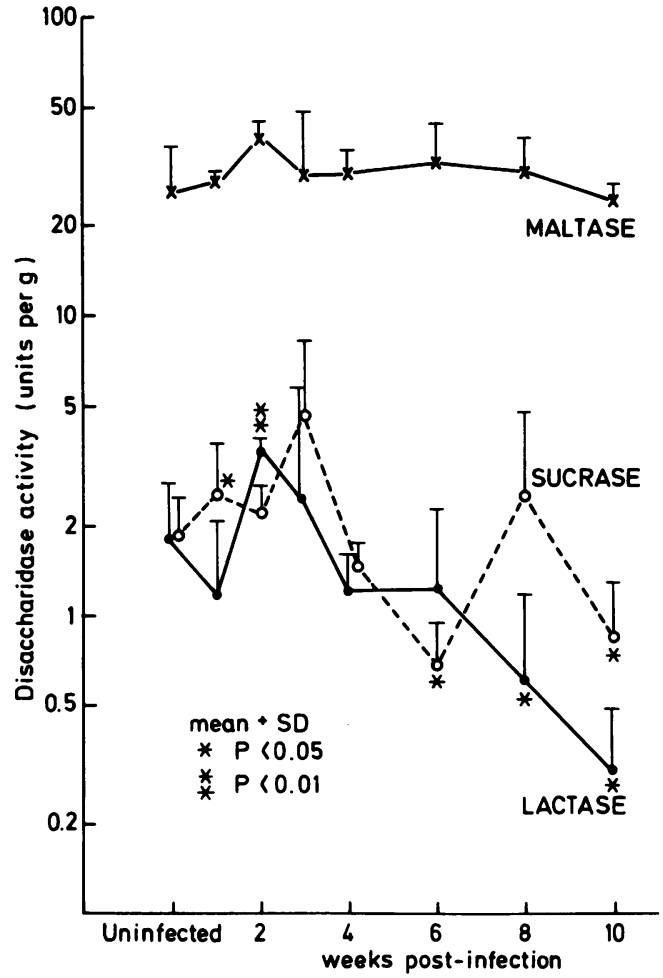

Fig. 6 Effects of primary Giardia muris infection on disaccharidase content of ileal mucosa, in CBA mice either uninfected, or at intervals from one to 10 weeks after Giardia muris infection.

SUMMARY OF THE ABNORMAL FEATURES

In Table 3 the features of abnormality of intestinal architecture, disaccharidases, and lymphocyte counts in these experiments are summarised. In jejunum, peak trophozoite numbers were present at two weeks with many parasites in the jejunum up to four weeks post-infection. A modest reduction in villus length and intraepithelial lymphocytes occurred at week 1 , and striking disaccharidase deficiencies at week 2 . This was followed by lengthening of the crypts of Lieberkuhn and a raised crypt cell production rate, peaking at week 3 . Later after infection, as trophozoite numbers fell, the intraepithelial count rose, and there was an increase in both the length of the villi and the disaccharidase actvity of the jejunum.

In contrast, in the ileum few or no trophozoites were present during the course of this infection. The only changes in the mucosa of the ileum in the early phase were an increase in the content of sucrase and lactase at weeks 1 and 2 respectively, and a decrease in crypt cell production rate and intraepithelial 


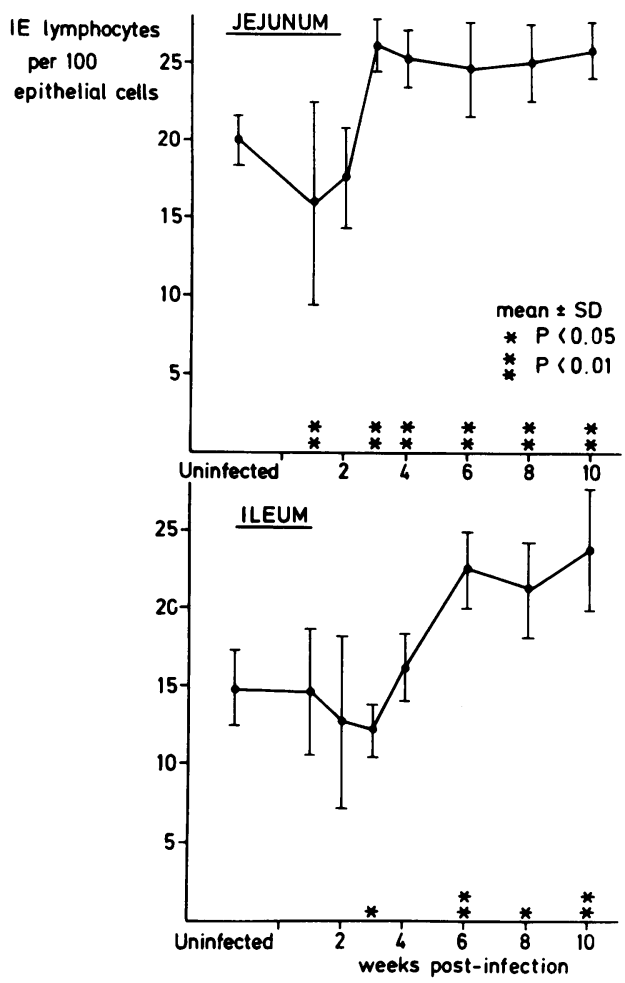

Fig. 7 Effects of Giardia muris infection of CBA mice on intraepithelial lymphocyte counts in jejunum and ileum. Six animals per group.

lymphocyte count at week 3 . Surprisingly, however, in specimens taken eight and 10 weeks postinfection there was evidence of a reduction in the length of both crypts and villi, a reduced crypt cell production rate, and reduced disaccharidase activity. A rise in intraepithelial lymphocyte count, similar to that seen in the jejunum, also occurred.

\section{Discussion}

There is enormous variability in both the clinical features and pathological changes associated with giardiasis in man. The reasons for this are not known, but symptoms have been shown to correlate with the degree of pathological damage to the small intestine. ${ }^{2}{ }^{8}$ There is thus a spectrum of severity, but at present we have little knowledge of the relative contributions of parasite and host-related factors to the clinical picture. The animal model of the disease developed by Roberts-Thompson et al ${ }^{9}$ provides the means whereby these components can be analysed separately. For example, changes caused directly by the parasite will vary in severity with the number of trophozoites at any given site. Changes resulting from the host response, on the other hand, can be identified by manipulating host factors such as immunity and nutrition, while taking care to monitor parasite numbers in addition.

The mouse model of the infection has been shown to be a useful and reproducible system for this type of work. ${ }^{9}$ Our results on the time-course of the infection are similar to those of others. ${ }^{911} 17$ In addition we have developed a technique for enumerating the trophozoite load in the whole small intestine which gives much higher values than the previously used wash-through method, which has been recognised as leaving many parasites attached to the mucosa. ${ }^{18}$ Using this vibration method we have confirmed that the parasite load peaks at around two weeks post-infection in CBA mice, and then rapidly decreases in parallel with cyst excretion. It was previously believed that parasite elimination was complete at around six weeks post-infection, but this sensitive technique has enabled us to detect substantial numbers of trophozoites after six weeks, with $50 \%$ of the animals studied having detectable numbers of trophozoites at three months or more after infection. This lingering, low-grade infection represents a balance

Table 3 Summary of features of small intestinal pathology in primary Giardia muris infection of CBA mice

\begin{tabular}{|c|c|c|c|c|c|c|c|c|c|c|c|c|c|c|}
\hline & \multicolumn{7}{|c|}{ Jejunum (weeks post-infection) } & \multicolumn{7}{|c|}{ Ileum (weeks post-infection) } \\
\hline & 1 & 2 & 3 & 4 & 6 & 8 & 10 & 1 & 2 & 3 & 4 & 6 & 8 & 10 \\
\hline Trophozoites & Many & Max. & Many & Many & Few & Few & Few & Few & Few & Few & Few & None & None & None \\
\hline Villus length & & - & - & $\uparrow$ & $\uparrow$ & $\uparrow$ & $\uparrow$ & & & - & & - & $\downarrow$ & $\downarrow$ \\
\hline Crypt length & $\uparrow$ & $\uparrow$ & $\uparrow$ & $\uparrow$ & - & - & - & & & - & & - & $\downarrow$ & $\downarrow$ \\
\hline \multicolumn{15}{|l|}{ Crypt cell } \\
\hline production rate & - & - & $\uparrow$ & - & - & - & - & & & $\downarrow$ & & - & $\downarrow$ & $\downarrow$ \\
\hline Disaccharidases & - & $\downarrow$ & - & - & $\uparrow$ & $\uparrow$ & $\uparrow$ & - & $\uparrow$ & - & - & $\downarrow$ & $\downarrow$ & $\downarrow$ \\
\hline \multicolumn{15}{|l|}{ Intraepithelial } \\
\hline lymphocytes & $\downarrow$ & - & $\uparrow$ & $\uparrow$ & $\uparrow$ & $\uparrow$ & $\uparrow$ & - & - & $\downarrow$ & - & $\uparrow$ & $\uparrow$ & $\uparrow$ \\
\hline
\end{tabular}


between parasite virulence and host immunity, and we have shown in a separate study that corticosteroid treatment of these mice can cause recrudescence of the infection. ${ }^{11}$ There is, however, no doubt that the rapid diminution in parasite numbers at around six weeks is immunologically mediated, as it does not occur in T cell depleted animals. ${ }^{17}$ It has not yet been established whether the reduction in parasite numbers is effected by $T$ cells themselves, $T$ dependent antibody or $T$ cell stimulated macrophages.

The aim of the present study was to examine small intestinal epithelial cell kinetics and villus and crypt architecture, brush border enzyme activity, and intraepithelial lymphocyte counts throughout the course of infection, in order to establish which of the changes could be attributed directly to the parasite load and which were likely to be secondary to the host response. The most striking effect clearly attributable to the parasite itself was a reduction in brush border disaccharidase activity, particularly that of lactase, in the jejunum at two weeks post-infection. This result was in conflict with our original hypothesis that the changes in disaccharidases known to occur in giardiasis reflected the presence of an immature enterocyte population. ${ }^{19}$ In fact, the changes in intestinal architecture and epithelial cell kinetics were small in comparison with the drop in disaccharidase activity, and by week 3 , when changes in the crypts were maximal, disaccharidase activity had returned to normal. It has been recognised that the presence of Giardia adjacent to a sheet of columnar epithelial cells is accompanied by damage to the microvilli covering the luminal cell surface. ${ }^{20}$ This phenomenon has also been found in bacterial overgrowth of the small bowel. ${ }^{21} \mathrm{As}$ giardiasis and bacterial overgrowth frequently occur together, ${ }^{22} 23$ the precise mechanism whereby the brush border enzyme activity is reduced needs further investigation.

The changes in intestinal architecture early in the course of the infection consisted mainly of a very limited increase in crypt mitosis with villi of normal length. This is similar to the pattern of intestinal architecture which we found in chronic murine giardiasis, ${ }^{10}$ and also is similar to the chronic low-grade graft-versus-host disease of mice. ${ }^{24}$ Mucosal changes in graft-versus-host disease and in allograt rejection are caused by cell-mediated hypersensitivity. ${ }^{14} 24$ We have proposed that $\mathrm{T}$ cells secrete 'enteropathic' lymphokines which act directly on the crypt cells and stimulate mitosis. In a more vigorous cell-mediated reaction they may also lead to villus damage. This hypothesis has been supported by the work of Roberts-Thompson and Mitchell, ${ }^{17}$ who showed that the changes in the villus-crypt ratio of giardia infected athymic (nude) mice were augmented when the mice were reconstituted with lymphoid cells from non-infected donor mice.

There were significant changes in the intraepithelial lymphocyte counts in both jejunum and ileum. In the jejunum there was a significant reduction in the intraepithelial lymphocyte count at week 1 , but by week 3 , when parasite numbers were falling, the intraepithelial lymphocyte count was raised and remained so throughout the study. Similar changes occurred in the ileum but the changes appeared two to three weeks later. Intraepithelial lymphocytes are mainly $\mathrm{T}$ cell $\mathrm{s}^{25}$ and these results provide further evidence for involvement of $T$ cell mediated immune reaction during the expulsion phase in giardiasis. Intraepithelial lymphocyte counts have been found to be raised in the majority of adults and children with giardiasis who have been investigated for malabsorption. ${ }^{25}$ Our findings of a sustained rise in intraepithelial lymphocyte count after trophozoites have largely been eliminated suggests that the occasional isolated finding of a high intraepithelial lymphocyte count in the jejunal biopsy of a patient investigated for diarrhoea may indicate recent, self-cured protozoal infection. The fall in intraepithelial lymphocyte count early in the course of the infection is unexplained and would merit further study.

The changes in small bowel architecture late after infection (weeks 8 and 10) consisting, in the jejunum, essentially of an expansion in villus size with increased disaccharidase activity, and in the ileum of a diminution in villi and crypts with reduced disaccharidases, were entirely unexpected findings. The ileal changes tend to run in the opposite direction from those in the jejunum, and would be consistent with the remarkable adaptive properties of the ileum. As with the intraepithelial lymphocyte counts, these features illustrate how a relatively minor insult, albeit more or less localised to one part of the small bowel, may lead to prolonged alterations in epithelial cell turnover and in mucosal lymphoid cell populations throughout the intestine.

We are grateful to the staff of the Animal Unit, Western General Hospital, and to Miss G Paul and Miss F Allan, Mr A Sutherland, and Mr F Donnelly for technical assistance. This work was supported in part by a grant from the National Fund for Research into Crippling Diseases. 


\section{References}

1 Jennings W, Rowland R, Hecker $\mathrm{R}$ et al. The significance of lowered disaccharidase levels. Aust NZ J Med 1976; 6: 556-60.

2 Duncombe VM, Bolin TD, Davis AE et al. Histopathology in giardiasis: a correlation with diarrhoea. Aust NZ J Med 1978; 8: 392-6.

3 Ferguson A, McClure JP, Townley RRW. Intraepithelial lymphocyte counts in small intestinal biopsies from children with diarrhoea. Acta Paediatr Scand 1976; 65: 541-6.

4 Wright SG, Tomkins AM. Quantification of the lymphocyte infiltrate in jejunal epithelium in giardiasis. Clin Exp Immunol 1977; 29: 408-12.

5 Yardley JH, Takano J, Hendrix TR. Epithelial and other mucosal lesions of the jejunum in giardiasis. Jejunal biopsy studies. Bull Johns Hopkins Hosp 1964; 115: 389-406.

6 Barbieri D, De Brito T, Hoshino S et al. Giardiasis in childhood. Arch Dis Child 1970; 45: 466-72.

7 Wright SG, Tomkins AM, Ridley DS. Giardiasis: clinical and therapeutic aspects. Gut 1977; 18: 343-50.

8 Wright SG, Tomkins AM. Quantitative histology in giardiasis. J Clin Pathol 1978; 31: 712-16.

9 Roberts-Thompson IC, Stevens DP, Mahmoud AAF, Warren KS. Giardiasis in the mouse: an animal model. Gastroenterology 1976; 71: 57-61.

10 MacDonald TT, Ferguson A. Small intestinal epithelial cell kinetics and protozoal infection in mice. Gastroenterology 1978; 74: 496-500.

11 Nair KPV, Gillon J, Ferguson A. Corticosteroid treatment increases parasite numbers in murine giardiasis. Gut. 1981; 22: 475-80.

12 Clarke RM. Mucosal architecture and epithelial cell production in the small intestine of the albino rat. $J$ Anat 1970; 107: 519-29.

13 Wimber DR, Lamerton LF. Cell population studies on the intestine of continually irradiated rats. Radiat Res 1963; 18: 137-46.
14 MacDonald TT, Ferguson A. Hypersensitivity reactions in the small intestine. 3. The effects of allograft rejection and graft-versus-host disease on epithelial cell kinetics. Cell Tissue Kinet 1977; 10: 301-12.

15 Ferguson A, Murray D. Quantification of intraepithelial lymphocytes in human jejunum. Gut 1971; 12: $988-94$

16 Dahlquist A. Assay of intestinal disaccharidases. Analyt Biochem 1968; 22: 99-107.

17 Roberts-Thompson IC, Mitchell GF. Giardiasis in mice. I. Prolonged infections in certain mouse strains and hypothymic (nude) mice. Gastroenterology 1978; 75: 42-6.

18 Owen RL, Nemanic P, Stevens DP. Ultrastructural observations on giardiasis in a murine model. I. Intestinal distribution, attachment and relationship to the immune system of Giardia muris. Gastroenterology 1979; 76: 757-69.

19 Rey J, Schmitz J, Rey F, Jos J. Cellular differentiation and enzymatic defects. Lancet 1971; 2: 218.

20 Takano J, Yardley JH. Jejunal lesions in patients with giardiasis and malabsorption. An electron microscopic study. Bull Johns Hopkins Hosp 1965; 116: 413-29.

21 Wehman HJ, Lifschitz F, Terchberg S. Effects of enteric microbial overgrowth on small intestinal ultrastructure in the rat. Am J Gastroenterol 1978; 70: 249-58.

22 Tandon BN, Tandon RK, Satpathy BK, Shriniwa S. Mechanism of malabsorption in giardiasis: a study of bacterial flora and bile salt deconjugation in upper jejunum. Gut 1977; 18: 176-81.

23 Tomkins AM, Wright SG, Drasar BS, James WPT. Bacterial colonisation of jejunal mucosa in giardiasis. Trans R Soc Trop Med Hyg 1978; 72: 33-6.

24 Mowat AMcI, Ferguson A. Hypersensitivity reactions in the small intestine. 6. Pathogenesis of the graftversus-host reaction in the small intestinal mucosa of the mouse. Transplantation 1981; 32: 238-43.

25 Ferguson A. Intraepithelial lymphocytes of the small intestine. Gut 1977; 18: 921-37. 